\title{
Topographic power spectral density study of the effect of surface treatment processes on niobium for superconducting radio frequency accelerator cavities
}

\author{
Chen Xu, ${ }^{1,2}$ Hui Tian, ${ }^{1}$ Charles E. Reece, ${ }^{1}$ and Michael J. Kelley ${ }^{1,2}$ \\ ${ }^{1}$ Thomas Jefferson National Accelerator Facility, Newport News, Virginia 23606, USA \\ ${ }^{2}$ Applied Science Department, College of William \& Mary, Williamsburg, Virginia 23187, USA
}

(Received 16 December 2011; published 27 April 2012)

\begin{abstract}
Microroughness is viewed as a critical issue for attaining optimum performance of superconducting radio frequency accelerator cavities. The principal surface smoothing methods are buffered chemical polish (BCP) and electropolish (EP). The resulting topography is characterized by atomic force microscopy (AFM). The power spectral density (PSD) of AFM data provides a more thorough description of the topography than a single-value roughness measurement. In this work, one dimensional average PSD functions derived from topography of BCP and EP with different controlled starting conditions and durations have been fitted with a combination of power law, $K$ correlation, and shifted Gaussian models to extract characteristic parameters at different spatial harmonic scales. While the simplest characterizations of these data are not new, the systematic tracking of scale-specific roughness as a function of processing is new and offers feedback for tighter process prescriptions more knowledgably targeted at beneficial niobium topography for superconducting radio frequency applications.
\end{abstract}

DOI: 10.1103/PhysRevSTAB.15.043502

PACS numbers: $82.45 . \mathrm{Rr}, 82.80 . \mathrm{Fk}, 81.65 . \mathrm{Ps}$

\section{INTRODUCTION}

Particle accelerators play a steadily increasing role in an expanding range of scientific research. Their greater capabilities and superior cost for performance in many instances result in even more rapid growth for accelerators using superconducting radio frequency (SRF) cavities to power the beam. Niobium is the material most widely used for construction of SRF cavities because it has the highest superconducting transition temperature $\left(T_{c}=9.2 \mathrm{~K}\right)$ of the pure metals, sufficiently high critical magnetic field $\left(H_{c}>1700 \mathrm{Oe}\right)$ for SRF applications, and metallurgical properties adequate for fabrication and service load. The science, technology, and history of niobium SRF have recently been reviewed [1].

The shallow penetration $(\sim 40 \mathrm{~nm})$ of the rf into superconducting niobium lends great importance to SRF cavity interior surface chemistry and topography. These in turn are strongly influenced by the chemical etching "surface clean-up" that follows fabrication. The two widely practiced etch technologies are buffered chemical polish (BCP) and electropolish (EP). Typically, BCP solution, the 1:1:1 or 1:1:2 (volume) mixture of $\mathrm{HNO}_{3}(69 \%), \mathrm{HF}(49 \%)$, and $\mathrm{H}_{3} \mathrm{PO}_{4}(85 \%)$, flows end to end through the cavity at approximately $10^{\circ} \mathrm{C}$ for a time sufficient to remove the mechanically damaged and contaminated material, a layer about $100 \mu \mathrm{m}$ thick [2]. Meanwhile, EP uses a 1:10 (volume) mixture of hydrofluoric (49\%) and sulfuric acid

Published by the American Physical Society under the terms of the Creative Commons Attribution 3.0 License. Further distribution of this work must maintain attribution to the author(s) and the published article's title, journal citation, and DOI.
(96\%) at an applied voltage of 14-20 volts. Much work has been done at $20-35^{\circ} \mathrm{C}$, but lower temperatures appear to yield a smoother surface [3].

The Meissner effect excludes the rf magnetic field from the superconducting $\mathrm{Nb}$ cavity. The field is parallel to the cavity surface and most intense at the equator. It must deflect to accommodate any topographical features on the surface, raising the local intensity. If the local intensity exceeds the critical field, a local loss of superconductivity results. Absorption there of rf power causes local heating, expanding the affected volume. Repeated many times over the cavity surface, quality factor $Q_{o}$ is then reduced, more so at higher gradients. The SRF community seeks to move beyond this qualitative description to a quantitative understanding of the effect of topography sufficient to guide cavity processing.

To correlate topography and performance, a means of acquiring and analyzing topography data is needed. Data acquisition so far has been by stylus profilometer (SP) or atomic force microscopy (AFM). The data set is the vertical position of the probe at the sequence of lateral positions comprising the scan. Data analysis may be so simple as the average displacement from the mean vertical position $\left(R_{a}\right.$, roughness), which has proven insufficiently incisive for SRF purposes. The next level of analysis is to condition and Fourier transform the scan data to display the contribution at each lateral dimension, the power spectral density (PSD) [4]. The approach can be extended by separating the PSD into contributions related to families of surface features, as is done in the optics community [5]. These and related analyses probe the average characteristics of the surface. They are relatively insensitive to a small number of singular features, though a single major protrusion or pit 
may cause poor cavity performance. For these, a kind of approach that views singularities is needed [5].

We report here four sets of experiments relevant to SRF cavity processing to show what can be revealed by the more extensive data processing approaches.

\section{EXPERIMENTAL METHODS}

\section{A. Materials}

SRF cavities are typically fabricated from fine-grained ("FG", 20-50 $\mu \mathrm{m}$ ), $3 \mathrm{~mm}$ thick niobium sheet; its manufacture has been described recently [1]. In current practice, after fabrication is complete, the cavity is subjected to BCP etch sufficient to remove mass equal to $\sim 150 \mu \mathrm{m}$ thickness from the interior surface, annealed at $600-800^{\circ} \mathrm{C}$ in vacuum to remove hydrogen, subjected to EP sufficient to remove mass equal to $30 \mu \mathrm{m}$, and then baked at $125^{\circ} \mathrm{C}$ in vacuum for $24-48$ hours [6]. The FG specimens used here were cut from an untreated sheet of 10 by $10 \mathrm{~mm}$ square.

The possibility that grain boundaries may exert harmful effects, e.g., trapping impurities, has led to interest in fabricating cavities from the largest possible grain size, even single crystals. The vendors have responded by producing $\mathrm{Nb}$ ingots that are single crystals or have a large central grain surrounded by smaller grains at the periphery. Slices of suitable thickness are cut by (e.g.) a wire saw; the individual grains are clearly identifiable by orientation luster. The single crystal specimens ("SC") used here were cut by electrical discharge machining from within a large single grain and determined by electron backscatter diffraction (EBSD) to have a $\langle 110\rangle$ surface orientation.

Some materials were examined as cut, having the same surface finish as cavities in production (as received, "AR"). Others were subjected to careful polishing typical of preparation for metallography (nanopolish, "NP").

\section{B. Treatments}

\section{Genesis of topography in BCP etching: The effect of grain boundaries}

Many researchers, including ourselves [2], have shown images of polycrystalline niobium etched by BCP. These surfaces exhibit roughness on a vertical scale on the order of a few microns and a lateral scale comparable to the grain size, leading some to conclude that preferential etching is responsible. We examined four single crystal specimens as received, the same four after $30 \mu \mathrm{m}$ removal and the same four after a further $100 \mu \mathrm{m}$ removal.

\section{Genesis of topography in BCP etching: Initial effect of etching}

Two nanopolished FG specimens were examined as received, after $\mathrm{BCP}$ for a time expected to remove $3 \mu \mathrm{m}$ and the same two after a time expected to remove a further $3 \mu \mathrm{m}$.

\section{Smoothing in EP: Initial smoothing}

Four FG specimens subjected to $100 \mu \mathrm{m} \mathrm{BCP}$ were then subjected to EP treatments at $20^{\circ} \mathrm{C}$ expected to remove 5 , 10 , or $15 \mu \mathrm{m}$, one each. These conditions were chosen to explore the start of EP in the latest current production etch practice.

\section{Smoothing in EP: Cumulative heavy etching}

Four FG materials, previously subjected to $100 \mu \mathrm{m}$ $\mathrm{BCP}$, were subjected to $\mathrm{EP}$ treatments at $30^{\circ} \mathrm{C}$, removing mass equivalent to $12,24,36$, or $48 \mu \mathrm{m}$, spanning the production range. The higher temperature was used here because it is typical of most previous reported work.

\section{Characterization}

As previously [4,5], the topography was examined by a Digital Instruments Nanoscope IV AFM using tips with diameter $<10 \mathrm{~nm}$, eigenfrequency $75 \mathrm{KHz}$, and Young's modulus $7.5 \mathrm{Nano} / \mathrm{m}$. A typical AFM data set consists of 512 scans of 512 data points each. The lateral resolution of the AFM is determined by the distance between sampling points. So for a $100 \mu \mathrm{m}$ scan of 512 points, the resolution is $100 \mu \mathrm{m} / 512=195 \mathrm{~nm}$. Two areas were scanned on all AR materials and at least four on all that were treated. When stylus profilometry (SP) was used, the measurements were obtained with a KLA-Tencor P-15 instrument with a $2 \mu \mathrm{m}$ diameter tip. The samples were scanned in three different regions each, with scan sizes of $1000 \mu \mathrm{m} \times 1000 \mu \mathrm{m}$, and the $1000 \mu \mathrm{m} \times 1000 \mu \mathrm{m}$ scan was taken as an array of 251 traces with 2501 points.

\section{Data analysis}

An initial way to view the data is in terms of familiar roughness numbers. Because a given sample might have curvature as well as the topographic features of interest, it can be useful to remove a simple polynomial background from the data set before determining the roughness numbers: detrending. Only after background correction is direct comparison of roughness values meaningful. In this paper, profile data were all subjected to third order polynomial detrending. Each of the 512 scans in each data set was detrended and each transform computed, and all 512 averaged to obtain the one dimensional average PSD, as before $[4,7]$. A root-mean-square (RMS) roughness value $\left(R_{q}\right)$ can be calculated as the square root of the integral of the PSD. To better reveal the impact of features of a particular lateral scale, the integral can be taken over the corresponding frequency range and compared to the total. 
In addition, an RMS slope of the profile or local angle $\left(R_{d q}\right)$ is also calculated according to ISO 25178 [8]:

$$
R_{d q}=\sqrt{\frac{1}{N} \sum_{i=1}^{N} \Delta_{i}^{2}}
$$

$\Delta_{i}=\frac{1}{60 d x}\left(y_{i+3}-9 y_{i+2}+45 y_{i+1}-45 y_{i-1}+9 y_{i-2}-y_{i-3}\right)$,

where $y_{n}$ are the height of adjacent points, $d_{x}$ is the step length; $N$ is the total number of points. This RMS slope can indicate the extent of local angle fluctuation. Intuitively, a surface with sharp angles will produce more possibility for hot spots because sharp angle features help enhance the local magnetic field above that at which flux enters the niobium and anomalous dissipation begins. An effective method to quantify them is needed.

Because of its wide data range, the PSD is best viewed as a $\log / \log$ plot. It has been found useful to further analyze the PSD in terms of three families of contributions [5,9,10]: (1) power law, evident as a straight line on the $\log / \log$ plot—stepped or "power" law topography can be responsible. For steps, the power law exponent reflects the internal angle; i.e., $90^{\circ}$ step results in power law exponent $n=2$, and smaller internal angles (sharper steps) give higher values; (2) $K$ (or ABC) correlation $-K$ correlation treats the surface as a Lorentzian height distribution on an otherwise perfect plane; (3) shifted Gaussian posits islands of a specific height and diameter - they could be adherent particles or an etching artifact. The visual appearance of the latter two components on a log-log plot is a constant value from low frequency to a turning point followed by a steep decline at higher frequency. It is often called a "shelf."

The fitting of the components to the experimental PSD is carried out by minimization of a merit function that is a measure of the difference between the experimental PSD and the theoretical model. Thus, if $P$ is the set of parameters that characterize the model under consideration, the merit function is defined by Eq. (3), in which the $\mathrm{PSD}_{\text {measured }}$ is calculated from the scan, while the $\mathrm{PSD}_{\text {fitted }}$ is the combination of the modeled components [11]:

$$
\operatorname{merit}(P)=\frac{1}{N} \sum_{t=1}^{N}\left[\log \operatorname{PSD}_{\text {measured }}\left(f_{i}\right)-\log \operatorname{PSD}_{\text {fitted }}\left(f_{i}\right)\right]^{2} \text {. }
$$

In this expression the $f_{i}$ are the spatial frequencies at which the measured PSD is evaluated and $N$ is the number of points at which the PSD is sampled. This merit function is a customized form of the chi-square function, widely used in the fitting of experimental data. The customization consists of subtracting the logarithm of the PSD's instead of the PSD themselves. Doing so is necessary because the values of the PSD function can extend over several orders of magnitude so that a direct comparison would give more weight to the spatial frequencies where the PSD value is higher. This form of merit function has been successfully applied to the fitting of angle resolved scattering measurements. Here, we use the trust region or LevenbergMarquardt algorithm in the Matlab ${ }^{\circledR}$ toolbox to obtain global minimization best fit.

\section{RESULTS}

\section{A. Single crystal niobium with incremental BCP treatment}

\section{Experimental data}

The $R_{q}$ and $R_{d q}$ calculated from a set of four single crystal samples are presented in Table I to show the reproducibility.

In Table I, the most important result is immediately evident. All the roughness values are 3 orders of magnitude smaller than seen for polycrystalline materials. Little change is evident from the initial removal $(30 \mu \mathrm{m})$ to even more removal than is typical of production (130 $\mu \mathrm{m}$ total). This suggests that BCP etching establishes a characteristic topography which remains substantially constant as the surface recedes.

Also note that the effect of detrending is significant for roughness, but not for angle, since the angle values arise from the local neighborhood while the roughness values are relative to the mean surface plane of the whole scan. Selected AFM images are presented in Fig. 1.

In Fig. 1, Note that the surface becomes effectively smooth after $30 \mu \mathrm{m} \mathrm{BCP}$ treatment; moreover, apparent

TABLE I. Summary of the effect of BCP treatment on topography of nanopolished single crystals.

\begin{tabular}{lcccccccccccc}
\hline \hline & \multicolumn{4}{c}{ As nanopolished } & \multicolumn{4}{c}{$30 \mu \mathrm{m}$ BCP } & \multicolumn{4}{c}{$130 \mu \mathrm{m} \mathrm{BCP}$} \\
Sample & $\mathrm{SC10}$ & $\mathrm{SC11}$ & $\mathrm{SC12}$ & $\mathrm{SC} 13$ & $\mathrm{SC} 10$ & $\mathrm{SC} 11$ & $\mathrm{SC} 12$ & $\mathrm{SC} 13$ & $\mathrm{SC10}$ & $\mathrm{SC} 11$ & $\mathrm{SC} 12$ & $\mathrm{SC} 13$ \\
\hline$R_{q}(\mathrm{~nm})$ & 62.3 & 18.0 & 7.43 & 11.9 & 5.03 & 5.44 & 13.4 & 10.5 & 8.26 & 11.5 & 7.98 & 4.38 \\
$R_{q}(\mathrm{~nm})$ detrended & 54.5 & 8.69 & 5.98 & 8.55 & 4.60 & 4.54 & 8.01 & 4.53 & 7.70 & 10.1 & 7.25 & 4.16 \\
$R_{d q}\left({ }^{\circ}\right)$ & 0.99 & 0.31 & 0.93 & 0.36 & 0.97 & 0.61 & 0.88 & 0.55 & 0.44 & 0.32 & 0.51 & 0.50 \\
$R_{d q}\left({ }^{\circ}\right)$ detrended & 0.99 & 0.30 & 0.93 & 0.36 & 0.97 & 0.61 & 0.87 & 0.55 & 0.44 & 0.36 & 0.51 & 0.50 \\
\hline \hline
\end{tabular}



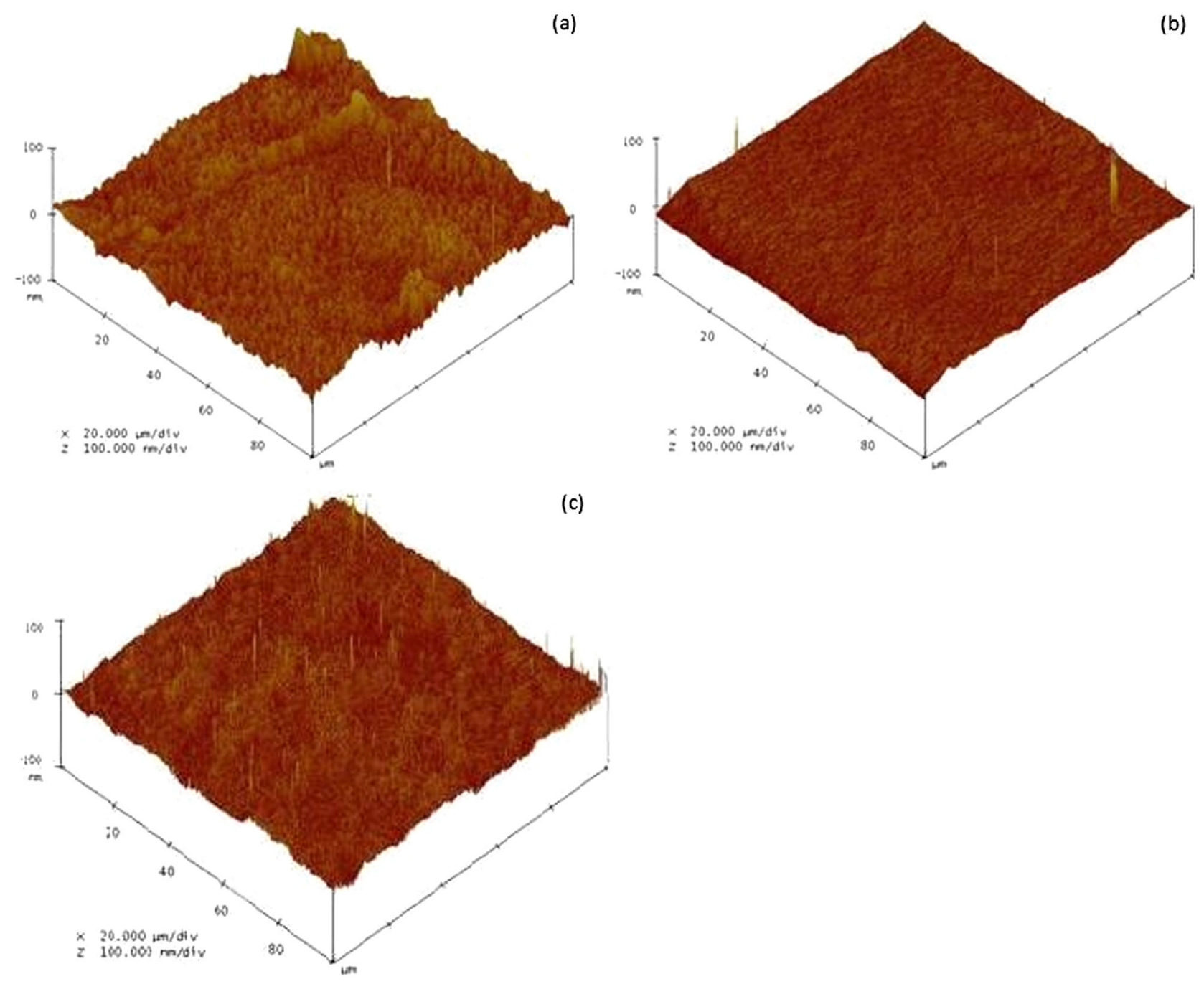

FIG. 1. AFM scans of single crystal 13 (a) NP as received, (b) after $30 \mu \mathrm{m} \mathrm{BCP,} \mathrm{and} \mathrm{(c)} \mathrm{after} 100 \mu \mathrm{m}$ additional BCP. Images are $20 \mu \mathrm{m}$ per division horizontally by $100 \mathrm{~nm}$ per division vertically.

roughness changes little after additional $100 \mu \mathrm{m}$ BCP treatment.

\section{PSD results and analysis}

Figure 2 presents a direct view of the PSD results. An average PSD was calculated for each state of each specimen; the associated colors are identified in the figure. This conveys a notion of specimen-to-specimen differences. Also plotted in gray are profiles of each state to indicate the span deviation in the statistical data. Even though $R_{q}$ from 30 and $130 \mu \mathrm{m} \mathrm{BCP}$ are almost the same (Table I), the PSD's reveal differences, illustrating the benefit of PSD analysis.

The PSD's of the as-received materials [Fig. 2(a)] display no systematic similarity. Convergence is becoming evident after the first $30 \mu \mathrm{m}$ removal, most so for frequencies above $10^{-4} \mathrm{~nm}^{-1}$ (lateral scale $10 \mu \mathrm{m}$ and shorter).
A further $100 \mu \mathrm{m}$ removal brings further convergence and decreased contribution at the highest frequency (shortest lateral scale). Evidently, there exists a surface topography characteristic of BCP etching which begins to be evident even after only a third as much material removal as typical production etching. Moreover, as noted in Table I, roughness values for these single crystal samples are on the order of 3 orders of magnitude less than those of typical polycrystalline materials treated by $\mathrm{BCP}$ [7].

Figure 3 presents the experimental PSD for these materials together with the calculated fits for each. The dominant character that emerges with increased material removal is $K$ correlation.

In Fig. 3, the contribution having the highest value in each region is indicated by a solid line and was used for the fitting. Generally, the PSD from as-received PSD and $30 \mu \mathrm{m}$ BCP-treated samples are fitted with combination of $K$ correlation, power law, and shifted Gaussian models, 

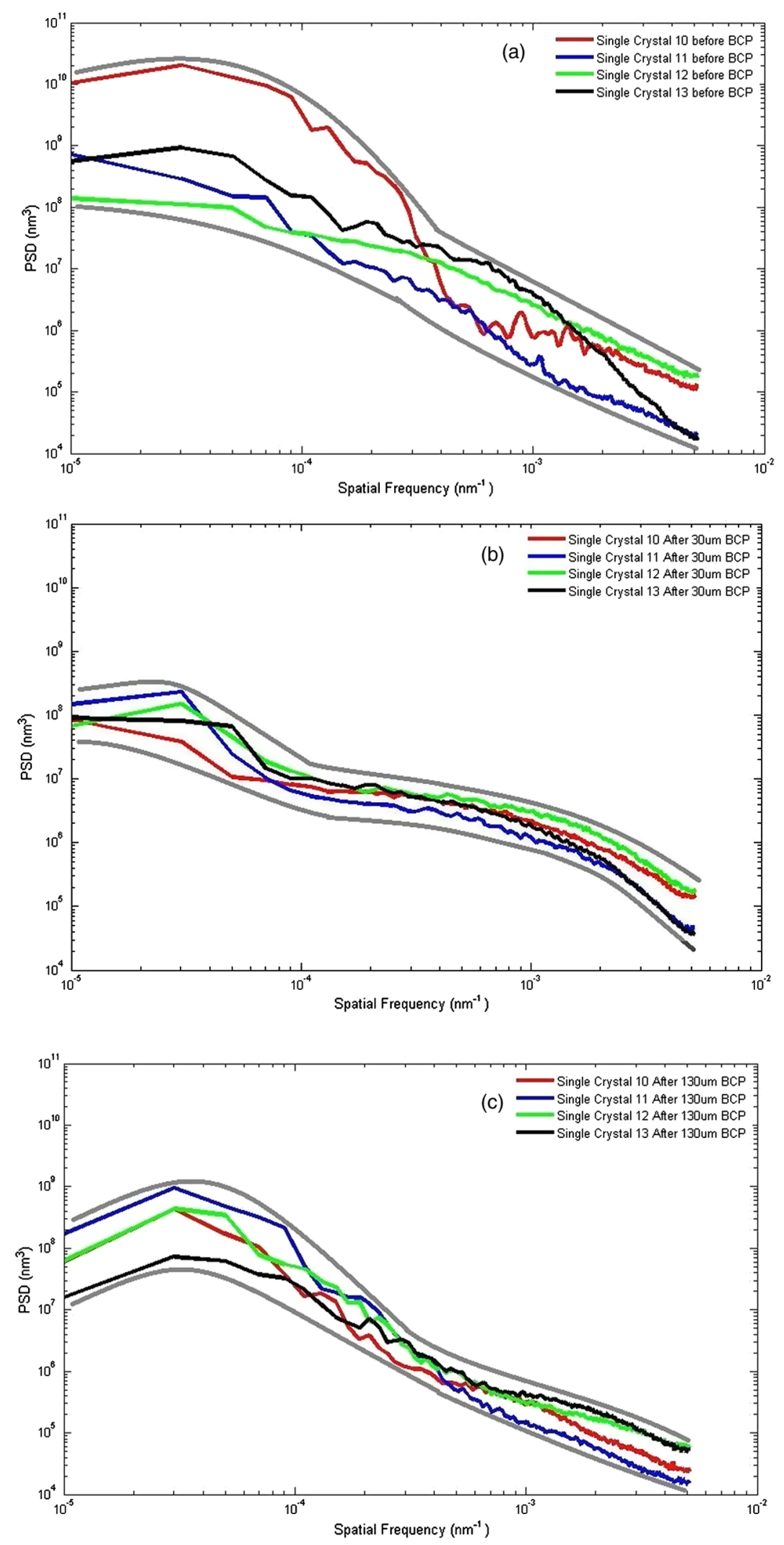

FIG. 2. The one dimension average PSD from four single crystal samples. (a) NP as received, (b) $30 \mu \mathrm{m}$ BCP, and (c) $100 \mu \mathrm{m}$ additional BCP. The gray lines in each are the highest and lowest PSD for each state to indicate the spread in the total data. 

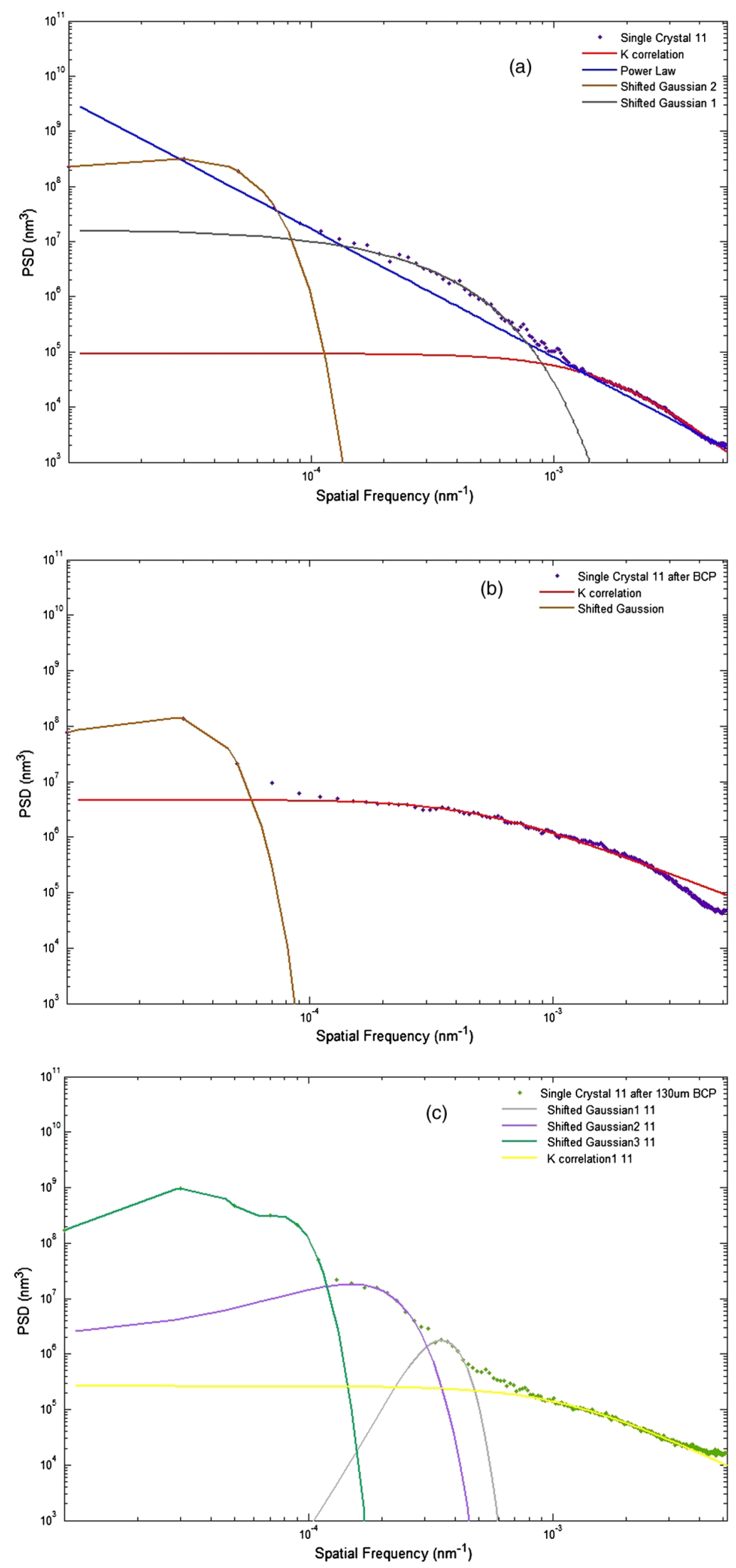

FIG. 3. Selected curve fitting PSD with different models (fitting on average 1D PSD) for Table I with different fitting components. Parts (a), (b), (c), and (d) show PSD from samples 10, 11, 12, and 13, respectively. From left to right figures show the PSD analysis on the same sample subjected from as-received, $30 \mu \mathrm{m}$ removed, and $130 \mu \mathrm{m}$ total material removal by BCP treatment. 
TABLE II. The fitting parameters of single crystal samples (unit: nm) for Fig. 3.

\begin{tabular}{|c|c|c|c|c|c|c|c|c|c|c|c|c|c|c|}
\hline \multirow{2}{*}{\multicolumn{2}{|c|}{$\begin{array}{l}\text { Model } \\
\text { Frequency range }\end{array}$}} & \multicolumn{3}{|c|}{$\begin{array}{c}K \text { correlation } \\
2.6 \times 10^{-4}-2.6 \times 10^{-3}\end{array}$} & \multicolumn{2}{|c|}{$\begin{array}{c}\text { Power law } \\
9.0 \times 10 \\
-5-2.6 \times 10^{-4}\end{array}$} & \multicolumn{3}{|c|}{$\begin{array}{l}\text { Shifted Gaussian model } \\
1.0 \times 10^{-4}-4 \times 10^{-4}\end{array}$} & \multicolumn{5}{|c|}{$\begin{array}{l}\text { Shifted Gaussian model } \\
1.0 \times 10^{-5}-1.0 \times 10^{-4}\end{array}$} \\
\hline & & A & B & $\mathrm{C}$ & $K_{n}$ & $n$ & Height & Size & Frequency & & eight & Size & & Frequency \\
\hline \multirow[t]{4}{*}{ As received } & 10 & $1.5 \times 10^{6}$ & 1537 & 1.1 & 59.9 & 1.3 & 3.5 & $2.6 \times 10^{3}$ & $1.3 \times 10^{-4}$ & & 6.0 & $7.8 \times 10$ & & $4.7 \times 10^{-5}$ \\
\hline & 11 & $9.2 \times 10^{4}$ & 561 & 2.6 & $1.0 \times 10^{-2}$ & 2.3 & 106.4 & $3.5 \times 10^{2}$ & $2.1 \times 10^{-3}$ & & 1.0 & $1.1 \times 10$ & & $2.7 \times 10^{-5}$ \\
\hline & 12 & $2.0 \times 10^{7}$ & 3854 & 1.1 & 35.0 & 1.4 & & & & & 0.5 & $1.0 \times 10$ & & $4.1 \times 10^{-5}$ \\
\hline & 13 & $1.3 \times 10^{7}$ & 1494 & 2.7 & $4.0 \times 10^{-2}$ & 2.3 & & & & & 1.1 & $1.0 \times 10$ & & $4.4 \times 10^{-5}$ \\
\hline \multicolumn{2}{|c|}{ Frequency range } & \multicolumn{3}{|c|}{$1.0 \times 10^{-4}-2.5 \times 10^{-3}$} & \multicolumn{2}{|l|}{$n / a$} & \multicolumn{8}{|c|}{$1.0 \times 10^{-5}-1.0 \times 10^{-4}$} \\
\hline \multicolumn{2}{|c|}{$30 \mu \mathrm{m}$} & A & B & $\mathrm{C}$ & $K_{n}$ & $n$ & \multicolumn{3}{|c|}{ Height } & \multicolumn{4}{|c|}{ Size } & Frequency \\
\hline \multirow[t]{4}{*}{$\mathrm{BCP}$} & 10 & $1.9 \times 10^{6}$ & 1268 & 1.1 & & & \multicolumn{3}{|c|}{0.3} & \multicolumn{4}{|c|}{$8.9 \times 10^{3}$} & $2.1 \times 10^{-5}$ \\
\hline & 11 & $1.8 \times 10^{6}$ & 1506 & 1.1 & & & \multirow{2}{*}{\multicolumn{3}{|c|}{$\begin{array}{l}0.3 \\
1.3\end{array}$}} & \multicolumn{4}{|c|}{$1.4 \times 10^{4}$} & $3.2 \times 10^{-5}$ \\
\hline & 12 & $2.3 \times 10^{6}$ & 1227 & 1.6 & & & & & & \multicolumn{4}{|c|}{$1.2 \times 10^{4}$} & $1.6 \times 10^{-5}$ \\
\hline & 13 & $2.6 \times 10^{6}$ & 1475 & 1.2 & & & \multicolumn{3}{|c|}{1.3} & \multicolumn{3}{|c|}{$1.1 \times 10^{4}$} & \multirow{2}{*}{\multicolumn{2}{|c|}{$\begin{aligned} & 1.8 \times 10^{-5} \\
& 1 \times 10^{-5}-7 \times 10^{-5}\end{aligned}$}} \\
\hline \multicolumn{2}{|c|}{ Frequency range } & \multicolumn{3}{|c|}{$7.0 \times 10^{-4}-5.0 \times 10^{-3}$} & \multicolumn{2}{|l|}{$n / a$} & \multicolumn{3}{|c|}{$2 \times 10^{-4}-2.6 \times 10^{-4}$} & \multicolumn{3}{|c|}{$7 \times 10^{-5}-2 \times 10^{-4}$} & & \\
\hline $130 \mu \mathrm{m}$ & & A & B & $\mathrm{C}$ & $K_{n}$ & $n$ & Height & Size & Frequency & Height & Size & Frequency & Height & Size Frequency \\
\hline \multirow[t]{4}{*}{$\mathrm{BCP}$} & 10 & $1.3 \times 10^{6}$ & 1763 & 1.1 & & & 0.2 & $5.5 \times 10^{3}$ & $2.0 \times 10^{-4}$ & 0.3 & $7.3 \times 10^{3}$ & $1.2 \times 10^{-4}$ & 0.3 & $4.3 \times 10^{4} 3.6 \times 10^{-5}$ \\
\hline & 11 & $2.6 \times 10^{6}$ & 905 & 1.1 & & & 0.2 & $3.5 \times 10^{3}$ & $3.5 \times 10^{-4}$ & 0.7 & $3.0 \times 10^{3}$ & $1.4 \times 10^{-4}$ & 0.9 & $1.8 \times 10^{4} 3.2 \times 10^{-5}$ \\
\hline & 12 & $3.8 \times 10^{6}$ & 532 & 1.1 & & & 0.4 & $4.2 \times 10^{3}$ & $2.2 \times 10^{-4}$ & 1.7 & $2.9 \times 10^{3}$ & $2.9 \times 10^{-5}$ & 0.8 & $1.5 \times 10^{4} 3.8 \times 10^{-5}$ \\
\hline & 13 & $5.7 \times 10^{6}$ & 583 & 1.2 & & & 0.9 & $1.7 \times 10^{3}$ & $1.2 \times 10^{-4}$ & 0.6 & $5.6 \times 10^{3}$ & $6.8 \times 10^{-5}$ & 0.4 & $1.0 \times 10^{4} \quad 4.1 \times 10^{-5}$ \\
\hline
\end{tabular}

while the $130 \mu \mathrm{m}$ BCP samples are fitted with multiple shifted Gaussian components at low frequency. Table II presents the fitting parameters for each of the four crystals at each of the three treatment stages.

\section{Discussion}

An important outcome of the PSD fitting is the behavior of the power law component. The exponent $(n)$ varies considerably for as-received material. Note that $n=2$ for a sharp $90^{\circ}$ step. After $30 \mu \mathrm{m}$ removal, $n$ is well below 2 , and no power law contribution is evident after $130 \mu \mathrm{m}$ removal. The absence of steps is consistent with the roughness value and the notion that steps are associated with grain boundaries, which are absent in single crystals. The absence of a power law component further indicates that single crystal surfaces, proxies for the grain interiors, have no power law component of consequence.

\section{B. Initial BCP treatment NP FG polycrystalline niobium}

Two nanopolished fine-grain samples were scanned at multiple locations, and $R_{q}$ values were calculated and are shown in Table III. BCP here are conducted with durations different from our previous work [5].

\section{Experimental data}

Table III shows that the $R_{q}$ and $R_{d q}$ increase from $28 \mathrm{~nm}$ to $84 \mathrm{~nm}$ to $155 \mathrm{~nm}$ and $0.4^{\circ}$ to $1.7^{\circ}$ to $3.8^{\circ}$, respectively. The detrending has little effect. This mainly is because the samples were polished "superflat" by vendor as the initial state. Accordingly, there is no major contour on the background, so that third order detrending had little effect on the $R_{q}$ values. Selected AFM images are presented in Fig. 4.

In Fig. 4, one can see step features emerge; note that the vertical scales are different in each figure. Especially significant is the development of sharp steps, even at this early stage of etching. Presumably they are grain boundaries, but specific evidence (e.g., EBSD on each side) is needed. A particularly significant aspect is that there appear to be elevation changes from each grain rather than grooves at grain boundaries. The observed topography is more consistent with differential etching of adjacent grains than with grain boundary attack. More can be learned by viewing AFM traces crossing such steps, represented by the black lines in Fig. 4.

In Fig. 5, two cursors are placed at the potential grain boundary. Note that the full-scale vertical distance is different for each plot. Previous work [5] also showed part of this

TABLE III. Summary of RMS values on the effect of BCP treatment on topography of fine-grained, nanopolished polycrystalline niobium.

\begin{tabular}{lcccccc}
\hline \hline Initial BCP $(\mathrm{nm})$ & \multicolumn{2}{c}{ Nanopolished } & \multicolumn{2}{c}{$3 \mu \mathrm{m}$ removal } & \multicolumn{2}{c}{$6 \mu \mathrm{m}$ removal } \\
Samples & $\mathrm{NP10}$ & $\mathrm{NP13}$ & $\mathrm{NP10}$ & $\mathrm{NP13}$ & $\mathrm{NP10}$ & $\mathrm{NP13}$ \\
\hline$R_{q}(\mathrm{~nm})$ & 35.5 & 47.0 & 87.1 & 71.0 & 154.9 & 98.2 \\
$R_{q}(\mathrm{~nm})$ Detrended & 27.7 & 46.8 & 84.1 & 70.1 & 154.9 & 98.1 \\
$R_{d q}\left({ }^{\circ}\right)$ & 0.4 & 0.9 & 1.7 & 2.2 & 3.8 & 2.5 \\
$R_{d q}\left({ }^{\circ}\right)$ Detrended & 0.4 & 0.9 & 1.7 & 2.2 & 3.8 & 2.6 \\
\hline \hline
\end{tabular}




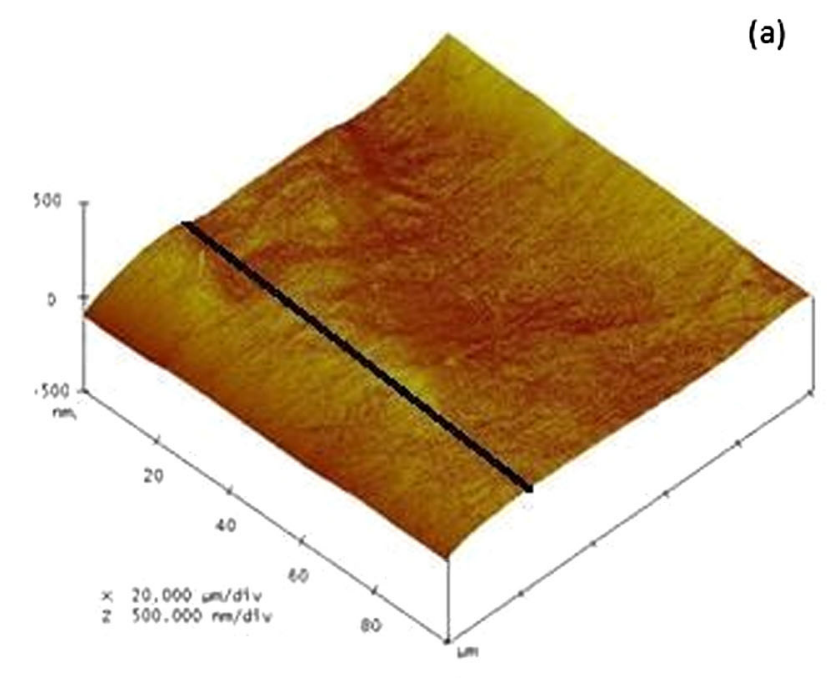

(a)
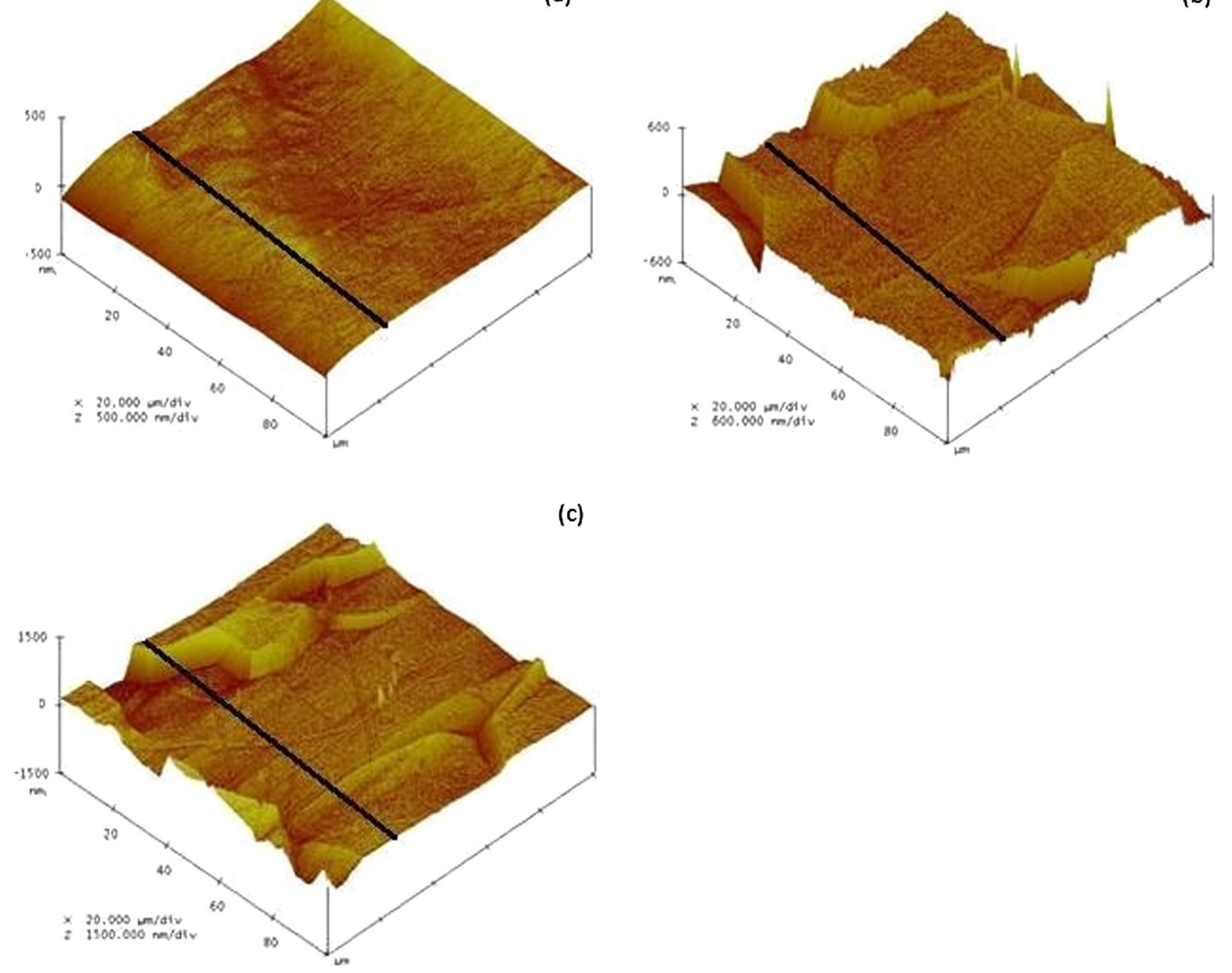

(c)

FIG. 4. AFM images of nanopolished polycrystalline niobium subjected initial BCP. All $20 \mu \mathrm{m}$ per horizontal division (a) nanopolished, $500 \mathrm{~nm}$ per vertical division, (b) after $3 \mu \mathrm{m}$ removal, $600 \mathrm{~nm}$ per vertical division, and (c) after $6 \mu \mathrm{m}$ removal, $1.5 \mu \mathrm{m}$ per vertical division. A selected line scan profile is chosen from each image and located in black.

figure. However, more analysis based on fast Fourier transform has been conducted to explore the mechanism of feature evolution. Length and angle measurements at the marked grain boundaries are given in Table IV.

\section{2. $P S D$ results and analysis}

The average PSD of each sample at each stage is presented in Fig. 6.

By viewing the intermediate transition during "shelf" structure to power law straight line, one can see the PSD increases in amplitude in the midfrequency range, 1-10 $\mu \mathrm{m}$ lateral length. This indicates features within that lateral range increase in height.

In Fig. 6, the PSD's of the nanopolished FG samples as received show a straight line character at mid and high frequencies with curvature at low frequencies: nominally a power law and a shelf. Presuming that nanopolishing is some variant of metallographic polishing, this topography could reflect random roughening at a very low level together with the signature of the polishing process (e.g., wheel vibration). The power law dimension $n$ for power law and height value from the shift Gaussian model both increase. These facts suggest the features at different wavelengths are all growing. However, the differences in fitting numbers suggest the growth rates vary. Modeling parameters for Fig. 6 are given in Table V.

\section{Discussion}

The impact of BCP is conditioned by the presence of grain boundaries, where differential etching yields topographic changes (see Fig. 5). The PSD shows the continuing evolution toward the power law character, reflecting a power law or stepped surface structure. The features of most concern for SRF performance are 

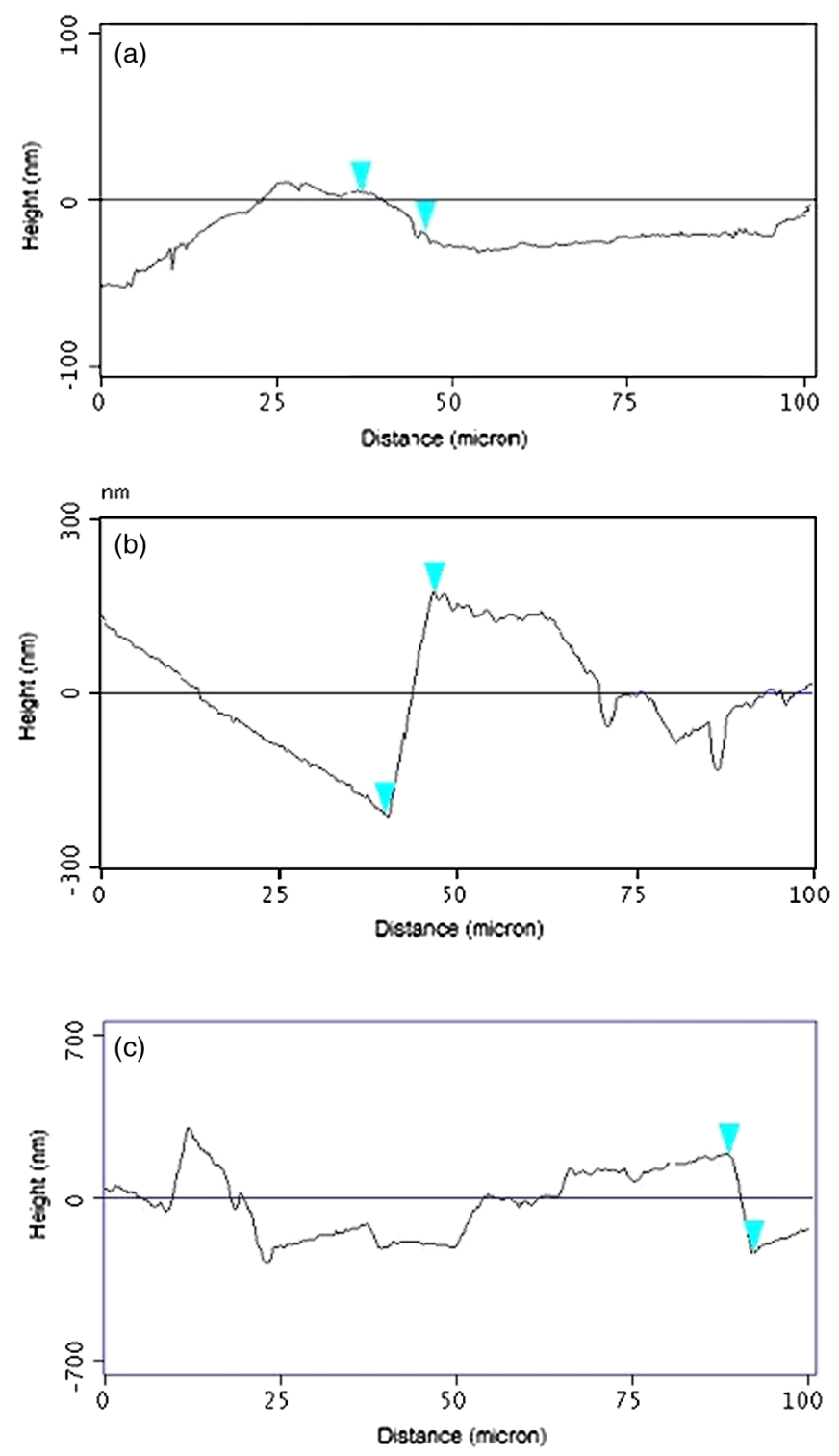

FIG. 5. Surface profiles of nanopolished polycrystalline $\mathrm{Nb}$ samples (a) as received, (b) after few- $\mu \mathrm{m}$ removal by $\mathrm{BCP}$, and (c) after a few $\mu \mathrm{m}$ additional removal by BCP.

the pronounced sharp edges at the apparent grain boundaries. The single crystals also evolve under BCP treatment, but do not have grain boundaries or a power law component to the PSD fit. Accordingly, the most reasonable attribution of the power law component here is the steps.
As noted above 1:1:2 fresh BCP solutions remove mass at a rate equivalent to a surface recession velocity of $3 \mu \mathrm{m} / \mathrm{min}$ at $25^{\circ} \mathrm{C}$. Two minutes BCP then results in about $6 \mu \mathrm{m}$ average thickness removal, implying a nominal height difference no more than several microns. In these two minutes however, the step height difference increases from $22 \mathrm{~nm} \rightarrow 379 \mathrm{~nm} \rightarrow 414 \mathrm{~nm}$. A large step develops quickly and maintains prominence with further etching. The limited scan length of AFM $(100 \mu \mathrm{m})$ vs grain size $(50-100 \mu \mathrm{m})$ impedes obtaining a statistically significant assessment of the distribution of step spacing and height. The application of other approaches is needed.

During sequential BCP, the major change in the PSD happens in the $10^{-4}$ to $10^{-3} \mathrm{~nm}^{-1}$ ( 1 to $10 \mu \mathrm{m}$ lateral lengths) frequency region. The corresponding lateral length is approximately the observed length of grain boundary inclines. As shown in Fig. 5, the grain boundary step height changes from $20 \mathrm{~nm}$ to $379 \mathrm{~nm}$ to $414 \mathrm{~nm}$, and the angle changes from $0.14 \mathrm{deg}$ to 3.9 deg to $6.7 \mathrm{deg}$, over a lateral scale of several microns. Therefore, within this lateral frequency range, onedimension averaged PSD spectrum amplitude increases overall. The single crystal results earlier indicate that intragrain roughness changes little with $\mathrm{BCP}$ polishing; its component in PSD is small. As a whole, after sufficient BCP etching, the PSD of polycrystalline material is dominated by a power law character, reflecting the large, sharp steps. This indicates that even a light BCP could destroy the smooth surface.

\section{a. Filter and profile reconstruction with PSD and Fourier transform (FT)}

The PSD pattern changes with $\mathrm{BCP}$ at different rate at different frequency. In order to investigate what components are changed by this $\mathrm{BCP}$ process, we propose to conduct an inverse windowed FT to reveal a feature with different lateral length evolving during this BCP etching.

From Fig. 6, one observes that major changes in the PSD fall within the $6 \times 10^{-5}$ to $10^{-3} \mathrm{~nm}^{-1}$ frequency range. To find its contribution to the change, we can reconstruct the surface by inverse Fourier transform of the PSD over this range. That is, using the PSD, one can reconstruct the surface profile corresponding to the selected frequency range to display the features which fall in corresponding lateral space values $[11,12]$. PSD, which is the modulus of

TABLE IV. Lateral lengths and angles between given two cursors shown in Fig. 5.

\begin{tabular}{lccc}
\hline \hline Between two cursors: & Nanopolished & $3 \mu \mathrm{m}$ removal & $6 \mu \mathrm{m}$ removal \\
\hline Lateral distance $(\mathrm{nm})$ & 9.2 & 6.8 & 3.5 \\
Vertical distance $(\mathrm{nm})$ & 22.8 & 380.0 & 415.0 \\
Angle (degree) & 0.1 & 3.9 & 6.7 \\
\hline \hline
\end{tabular}



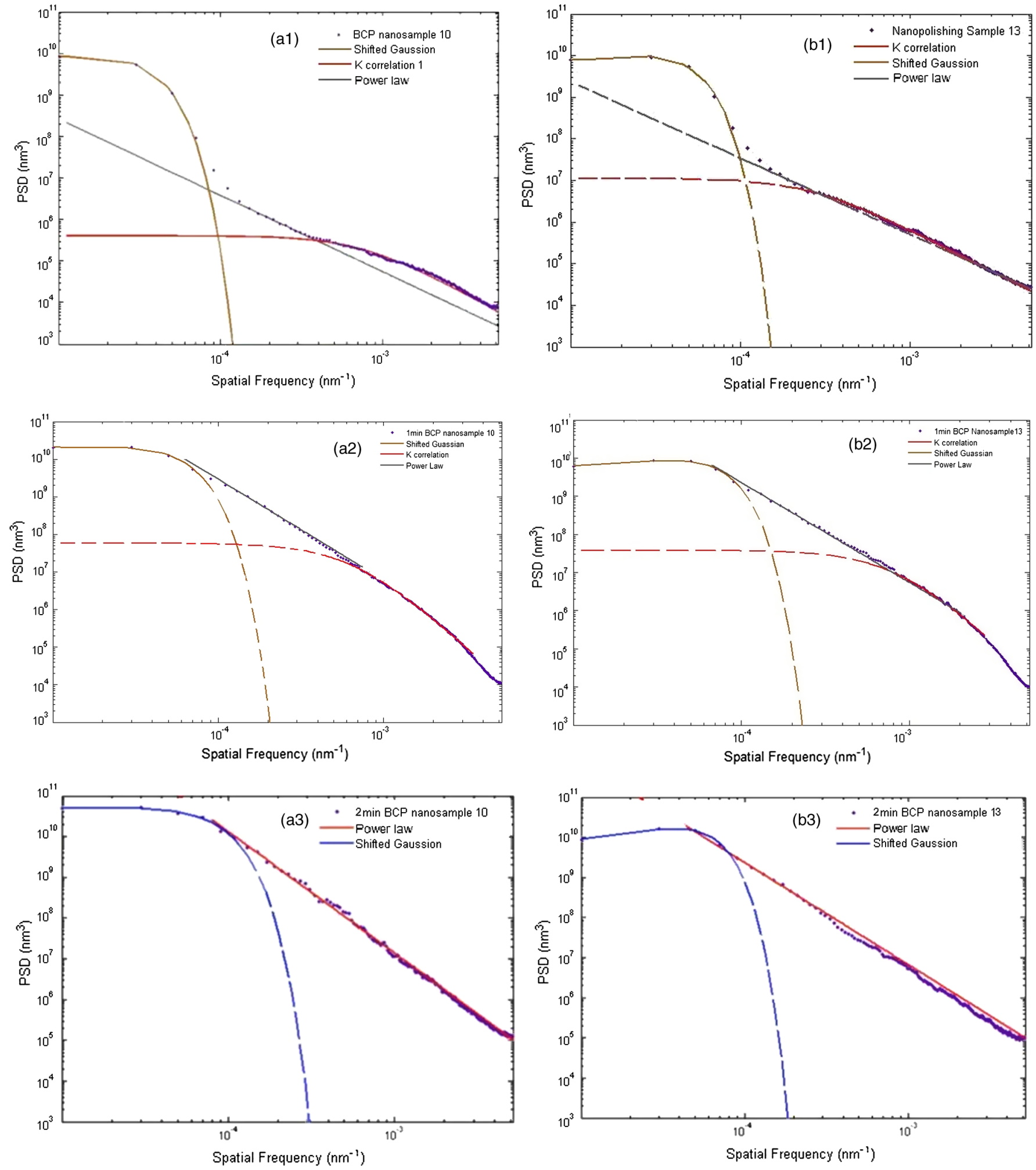

FIG. 6. Averaged 1D PSD of nanopolished FG samples shown in Fig. 4.

the FT, will convolute the real and imaginary parts. In order to invert the FT, the cutoff filter is multiplied directly on the FT components, not the PSD, to retain the imaginary part.
Figure 7 reveals features of the profile originating within a specific lateral spatial range. Figure 7(b) represents features with length from 1 to $16 \mu \mathrm{m}$; Fig. 7(c) represents features with length falling between $195 \mathrm{~nm}$ and $1 \mu \mathrm{m}$. 
TABLE V. The fitting parameter of two samples (unit: nm) for Fig. 6.

\begin{tabular}{|c|c|c|c|c|c|c|c|c|c|}
\hline \multirow[b]{2}{*}{ Model } & \multirow[b]{2}{*}{ Sample } & \multicolumn{3}{|c|}{$K$ correlation } & \multicolumn{2}{|c|}{ Power law } & \multicolumn{3}{|c|}{ Shifted Gaussian } \\
\hline & & $A$ & B & $C$ & $K_{n}$ & $n$ & Height & Size & Frequency \\
\hline Frequency & & \multicolumn{3}{|c|}{$4 \times 10^{-4}-5 \times 10^{-3}$} & \multicolumn{2}{|c|}{$1 \times 10^{-4}-3 \times 10^{-4}$} & \multicolumn{3}{|c|}{$1 \times 10^{-5}-1 \times 10^{-4}$} \\
\hline \multirow[t]{2}{*}{ As received } & NP10 & $4.1 \times 10^{5}$ & 1356 & 1.2 & 0.2 & 1.8 & 4.3 & $1.2 \times 10^{4}$ & $1.2 \times 10^{-5}$ \\
\hline & NP13 & $1.1 \times 10^{7}$ & 3899 & 1.1 & 1.5 & 1.8 & 5.5 & $1.0 \times 10^{4}$ & $2.4 \times 10^{-5}$ \\
\hline Frequency & & \multicolumn{3}{|c|}{$8 \times 10^{-4}-5 \times 10^{-3}$} & \multicolumn{2}{|c|}{$1 \times 10^{-4}-8 \times 10^{-4}$} & \multicolumn{3}{|c|}{$1 \times 10^{-5}-1 \times 10^{-4}$} \\
\hline \multirow[t]{2}{*}{$6 \mu \mathrm{m}$ off } & NP10 & $3.8 \times 10^{7}$ & 1201 & 3.4 & $5.7 \times 10^{-2}$ & 2.6 & 11.7 & $6.9 \times 10^{3}$ & $1.8 \times 10^{-5}$ \\
\hline & NP13 & $3.8 \times 10^{7}$ & 1201 & 3.1 & $7.4 \times 10^{-2}$ & 2.6 & 7.9 & $6.5 \times 10^{3}$ & $3.7 \times 10^{-5}$ \\
\hline Frequency & & \multicolumn{3}{|c|}{$n / a$} & \multicolumn{2}{|c|}{$1 \times 10^{-4}-5 \times 10^{-3}$} & \multicolumn{3}{|c|}{$1 \times 10^{-5}-1 \times 10^{-4}$} \\
\hline \multirow[t]{2}{*}{$12 \mu \mathrm{m}$ off } & NP10 & & & & 0.1 & 2.9 & 27.4 & $4.6 \times 10^{-3}$ & $1.7 \times 10^{-5}$ \\
\hline & NP13 & & & & 0.1 & 2.5 & 8.1 & $8.9 \times 10^{-3}$ & $3.7 \times 10^{-5}$ \\
\hline
\end{tabular}

There is a dramatic difference between them because BCP preferentially accentuates grain boundaries. One can see that major $R_{q}$ contribution comes from the low frequency $\left(1.0 \times 10^{-4} \sim 1.0 \times 10^{-3} \mathrm{~nm}^{-1}\right)$, while minor contribution is found at higher frequency $\left(2.0 \times 10^{-3}-5 \times\right.$ $10^{-3} \mathrm{~nm}^{-1}$ ).

\section{Case 3: Initial EP conversion of BCP}

Taking the view that process determines topography, how rapidly does a change of process (BCP to EP) reach steady state? Four fine-grained $\mathrm{Nb}$ samples were subjected together to $100 \mu \mathrm{m}$ removal by BCP. One was kept as a $\mathrm{BCP}$ record and each of the others was electropolished at $20^{\circ} \mathrm{C}$ to remove 5,10 , or $15 \mu \mathrm{m}$.

\section{Experimental data}

A series of four fine-grained samples were BCP and EP polished. Resulting $R_{q}$ and $R_{d q}$ are presented in Table VI.

In Table VI, roughness and local angle show only modest or no change because of the very short EP duration. However, detrending the data reveals that $R_{q}$ changes, indicating that the background is not flat. Moreover, the nondetrended $R_{q}$ shows no trends of decrease, but detrended ones do, reinforcing the importance of detrending. Selected AFM images are shown in Fig. 8.

The AFM micrographs in Fig. 8 show that the rough surface becomes visually smoother and less sharp, and the edge features become round, though RMS values show little change. Another interesting feature in Fig. 8(b) illustrates that, at very early stages of EP, small edge steps emerged, while later EP eliminated these features in Figs. 8(c) and 8(d).

\section{PSD results and analysis}

In Fig. 9, PSD from AFM are fitted. The AFM frequency range is within $2 \times 10^{-5}$ to $1 \times 10^{-2} \mathrm{~nm}^{-1}$ in frequency.
In Fig. 9, separate PSD are fitted with a combination of three components and corresponding parameters are given in Table VII.

In Fig. 9, after $5 \mu \mathrm{m}$ removal by EP, the PSD has significantly transformed from power law structure into a shelf structure. The dramatic change is readily evident in the PSD but not in $R_{q}$. Net removal of only $5 \mu \mathrm{m}$ cannot be expected to significantly change the height variation, which underlies the roughness values. However, localized attenuation of sharp projections can have a major impact on the power law contribution. Further, the PSD intensity in the frequency range $4 \times 10^{-4}-4 \times$ $10^{-3} \mathrm{~nm}^{-1}$ (few tenths to few micron lateral scale) actually increases as material is removed from these samples by the EP.

\section{Full EP conversion of BCP}

As a further comparison, another series of BCP-treated fine-grained samples were subjected to EP for times typical of SRF cavity production at (the more typically used) $30^{\circ} \mathrm{C}$ to remove $12,24,36$, or $48 \mu \mathrm{m}$. These latter materials have been described briefly previously [6].

Scanned sample $R_{q}$ and $R_{d q}$ values presented in Table VIII and AFM images are selectively shown in Fig. 11. Note the scanned areas are $100 \mu \mathrm{m}$ by $100 \mu \mathrm{m}$.

With these larger removals, roughness and local angle values fall.

Figure 10 clearly shows that sharp edges and steps are removed even at the earliest stage sampled in this sequence of EP processing. In Figs. 10(c)-10(e), the edges and steps are inconsequential, while the same very small features come up and become ubiquitous.

PSDs were calculated from Fig. 10, fitted in Fig. 11, and corresponding fit parameters are given in Table IX.

The fitted shifted Gaussian model indicates reduced island height, while the macro range size $(\sim 20 \mu \mathrm{m})$ and frequency shift of the islands remain stable. This stability may simply reflect the grain size of the material, 

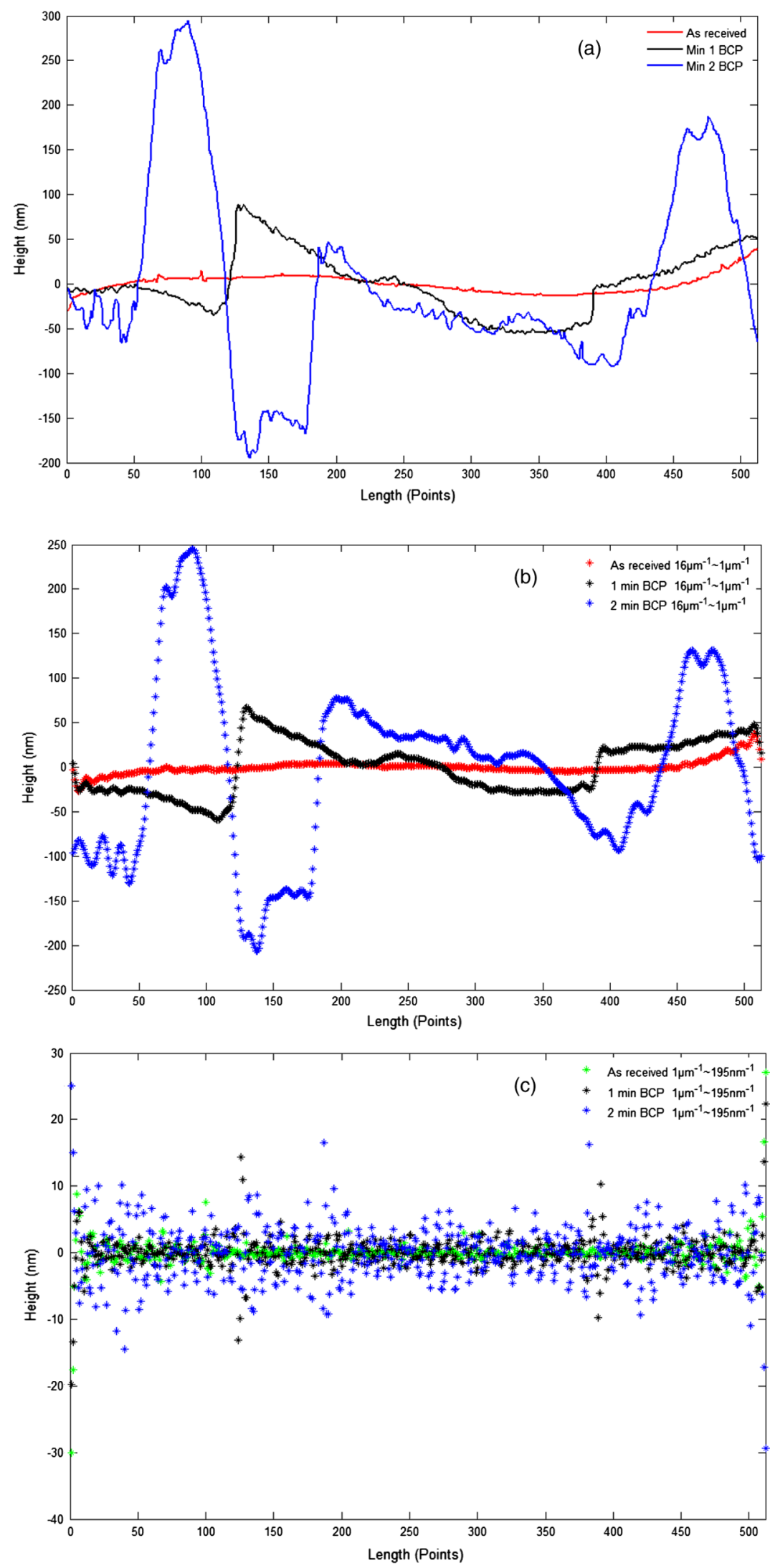

FIG. 7. A series of surface of $N=512$ points (a), original surface; (b), midfrequency bandpass range $16 \mu \mathrm{m}^{-1} \sim 1 \mu \mathrm{m}^{-1}$; (c), high pass range $1 \mu \mathrm{m}^{-1} \sim 195 \mathrm{~nm}^{-1}$. 
TABLE VI. Effect of initial EP on fine-grained $\mathrm{Nb}$ previously subjected to BCP.

\begin{tabular}{lcccc}
\hline \hline & $100 \mu \mathrm{m}$ BCP only & Plus 5 $\mu \mathrm{m} \mathrm{EP}$ & Plus $10 \mu \mathrm{m} \mathrm{EP}$ & Plus 15 $\mu \mathrm{m} \mathrm{EP}$ \\
\hline$R_{q}(\mathrm{~nm})$ & 224.5 & 257.1 & 254.7 & 214.1 \\
$R_{q}(\mathrm{~nm})$ detrended & 169.2 & 163.2 & 162.3 & 138.3 \\
$R_{d q}\left({ }^{\circ}\right)$ & 2.9 & 3.8 & 4.5 & 3.5 \\
$R_{d q}\left({ }^{\circ}\right)$ detrended & 2.7 & 3.4 & 4.3 & 3.3 \\
\hline \hline
\end{tabular}
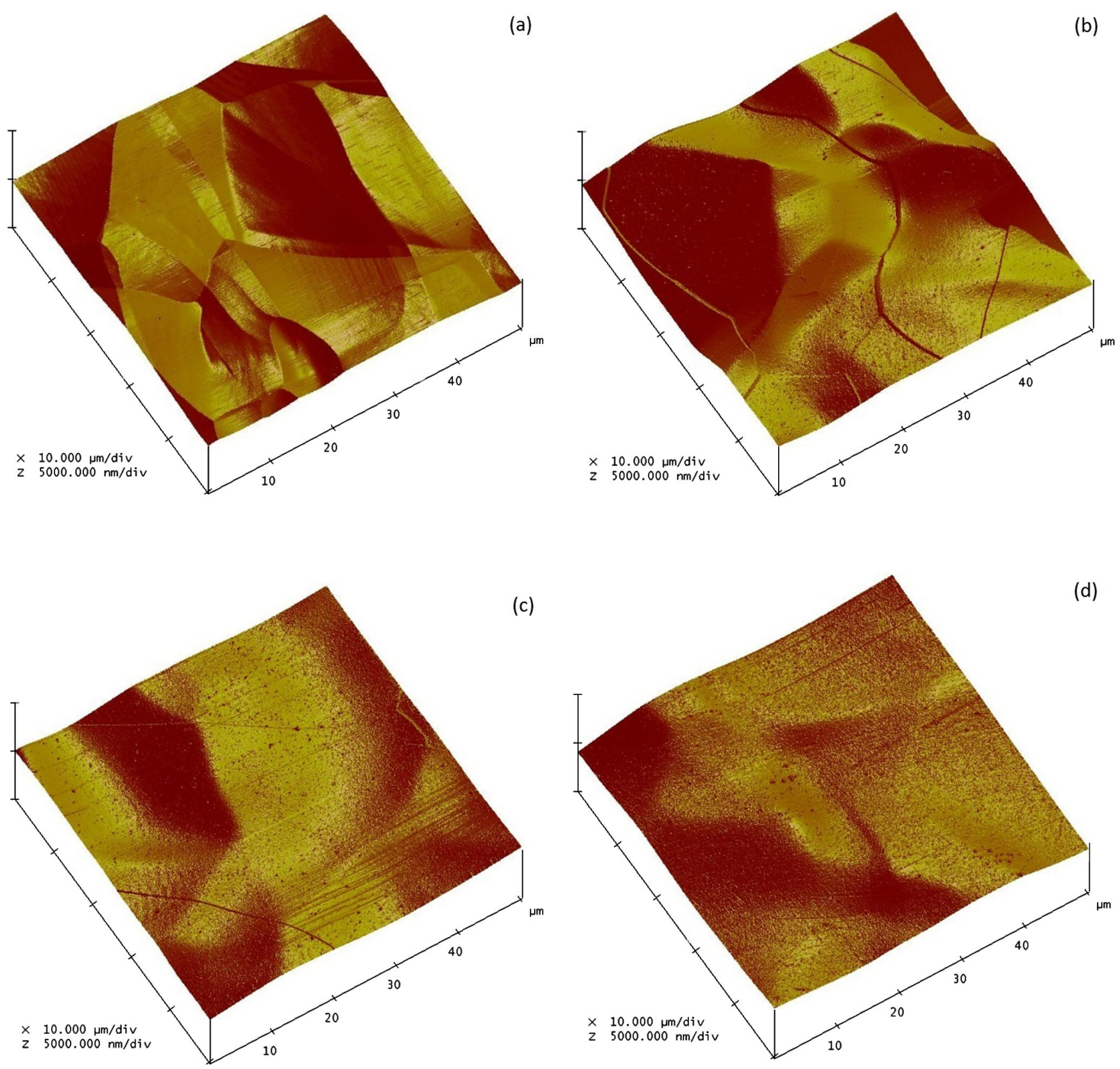

FIG. 8. AFM images from a FG niobium sample (a) after $100 \mu \mathrm{m} \mathrm{BCP}$ surface, then electropolished at $20^{\circ} \mathrm{C}$ to remove (b) $5 \mu \mathrm{m}$, (c) $10 \mu \mathrm{m}$, and (d) $15 \mu \mathrm{m}$. $10 \mu \mathrm{m}$ per horizontal division and $5 \mu \mathrm{m}$ per vertical division. 

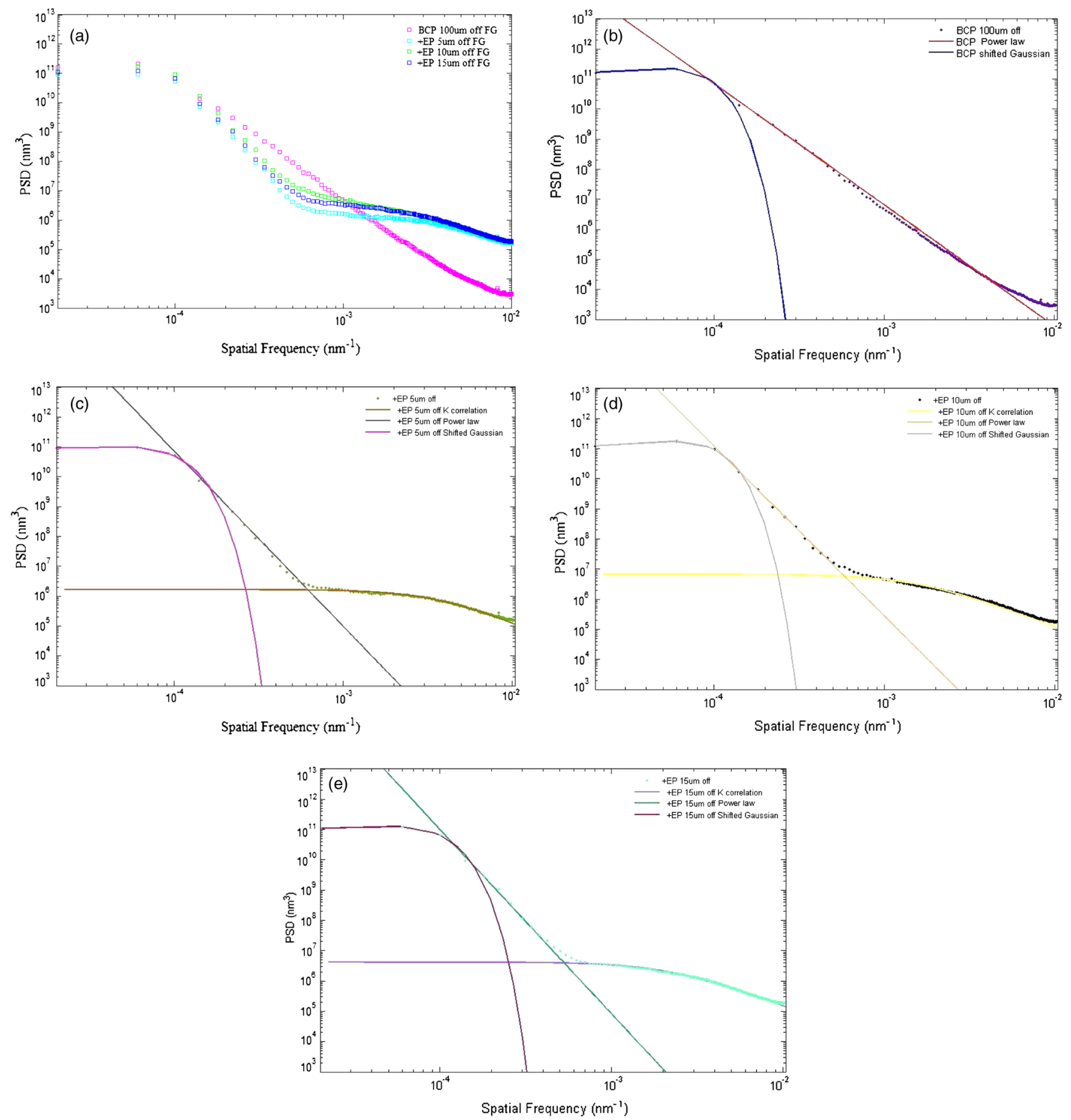

FIG. 9. PSD direct comparison. (a) A set of four PSD, (b) BCP, (c) $+5 \mu \mathrm{m} \mathrm{EP,} \mathrm{(d)}+10 \mu \mathrm{m} \mathrm{EP}$, and (e) $+15 \mu \mathrm{m}$ EP PSD with regional fitting. These short duration electropolishing treatments are conducted at $20^{\circ} \mathrm{C}$ and $\mathrm{AFM}$ scanned with size $50 \mu \mathrm{m} \times 50 \mu \mathrm{m}$.

and the reducing "island" height is the reduction of height variation across individual grains. The inclusion of SP data here confidently includes a statistically large number of grains.

\section{Discussion}

While the total roughness values changed little with initial EP (Table VI), a significant change is seen here with more polishing time (Table VIII), consistent 
TABLE VII. The fitting parameter of samples (unit: nm) for Fig. 9 (frequency range applicable).

\begin{tabular}{|c|c|c|c|c|c|c|c|c|}
\hline \multirow[b]{2}{*}{ Model } & \multicolumn{3}{|c|}{$K$ correlation } & \multicolumn{2}{|c|}{ Power law } & \multicolumn{3}{|c|}{ Shifted Gaussian } \\
\hline & $A$ & $B$ & $C$ & $K_{n}$ & $n$ & Height & Size & Frequency \\
\hline Frequency & \multicolumn{3}{|c|}{$7 \times 10^{-4}-1 \times 10^{-2}$} & \multicolumn{2}{|c|}{$2 \times 10^{-4}-8 \times 10^{-4}$} & \multicolumn{3}{|c|}{$1 \times 10^{-5}-2 \times 10^{-4}$} \\
\hline $\mathrm{BCP}$ & & & & $5.1 \times 10^{-6}$ & 4.0 & 41.2 & $6.5 \times 10^{3}$ & $4.8 \times 10^{-5}$ \\
\hline$+5 \mu \mathrm{m} \mathrm{EP}$ & $1.65 \times 10^{6}$ & 265.7 & 1.5 & $2.3 \times 10^{-13}$ & 5.9 & 37.6 & $4.8 \times 10^{3}$ & $4.4 \times 10^{-5}$ \\
\hline$+10 \mu \mathrm{m} \mathrm{EP}$ & $6.58 \times 10^{6}$ & 657.6 & 1.1 & $2.9 \times 10^{-12}$ & 5.6 & 42.3 & $5.6 \times 10^{3}$ & $5.5 \times 10^{-5}$ \\
\hline$+15 \mu \mathrm{m} \mathrm{EP}$ & $4.18 \times 10^{6}$ & 474.4 & 1.1 & $4.4 \times 10^{-14}$ & 6.1 & 40.5 & $5.0 \times 10^{3}$ & $4.6 \times 10^{-5}$ \\
\hline
\end{tabular}

TABLE VIII. Effect of full EP conversion on fine-grained Nb previously subjected to $100 \mu \mathrm{m} \mathrm{BCP}$.

\begin{tabular}{|c|c|c|c|c|c|}
\hline & $100 \mu \mathrm{m} \mathrm{BCP}$ only & Plus $12 \mu \mathrm{m} \mathrm{EP}$ & Plus $24 \mu \mathrm{m} \mathrm{EP}$ & Plus $36 \mu \mathrm{m} \mathrm{EP}$ & Plus $48 \mu \mathrm{m}$ EP \\
\hline$R_{q}(\mathrm{~nm})$ & 502.7 & 206.3 & 121.1 & 141.7 & 32.6 \\
\hline$R_{q}$ detrended $(\mathrm{nm})$ & 501.8 & 205.2 & 121.0 & 88.5 & 31.5 \\
\hline$R_{d q}\left({ }^{\circ}\right)$ & 5.4 & 2.3 & 3.5 & 2.5 & 0.4 \\
\hline$R_{d q}\left({ }^{\circ}\right)$ detrended & 5.4 & 2.3 & 3.5 & 2.4 & 0.3 \\
\hline
\end{tabular}

with the notion that EP first attacks the sharpest edges and then continues to level projections. Again, most of the impact is in the few to few-tenths micron range. Recent evidence [4] indicates a temperature dependence in EP mechanisms, favoring polishing over etching at some scales at lower temperature, perhaps a factor in the difference evident between Figs. 9 and 11. Derived data from Table IX shows a good trend to smoother surface, although the power law value $n$ appears to increase at the midfrequency range together with decreasing amplitude $K_{n}$. This increase might be explained by different polishing rates at low and high frequency.

We note some character difference between the sample series III C 2 and III C 3, although they do not fully overlap. We intend to clarify if this is a consequence of differing process temperature in the near future.

\section{GENERAL DISCUSSION}

An observation spanning most of the materials examined is that BCP rapidly promotes the emergence of sharp features when grain boundaries are present and that EP rapidly attenuates them. While this qualitative characterization is not new, the harmonic content analysis is. In case 1 , the rapid effect is evident as a change in the power law contribution to the PSD before it appears in the simple roughness values. An intriguing question is: what matters for SRF? Simulation is needed as a first step. A desirable experiment is to examine the performance of a cavity subjected to heavy BCP in that state and again after EP sufficient to remove a few microns. It should be paired with the reverse experiment.
Variability is an issue. Even for single crystals processed together, the PSD's and the fitting parameters differ by more than a half order of magnitude. Differences are larger when grain boundaries are present, as may be anticipated. Are the observed differences between samples real or are they within sample differences? Certainly a factor is that the maximum AFM scan area is $100 \times 100 \mu \mathrm{m}$, not much different from the nominal grain size for FG materials, so grain boundary or grain orientation differential effects may not be thoroughly sampled within a single scan. A severalfold increase in the area examined for at least a few samples would be a step toward clarity.

Another feature is the crossover of PSD's for EP and $\mathrm{BCP}$ in the neighborhood of $1 \mu \mathrm{m}^{-1}$. The meaning is that at micron and smaller length scale, BCP is smoother and the reverse at longer scale. The EP process is understood to accomplish leveling by depletion of the active fluoride ion species in a layer adjacent to the surface having a thickness of a few tens of microns, depending on specific conditions [4]. At sufficiently small length scale, the difference in concentration of the fluoride ion species will be too small to contribute enhanced leveling. On this very fine scale there may be another process that needs consideration.

Finally, there is the behavior of the presumed grain boundaries in BCP. What leads to their prominence and what is the underlying mechanism? Can it be explained as differential etch rate due to variation of chemical potential with exposed face of niobium crystal? Indeed BCP needs to be understood with the same level of detail as is emerging for EP. If the roughening can be controlled, BCP has the appeal of being a much simpler process than EP as currently practiced. 


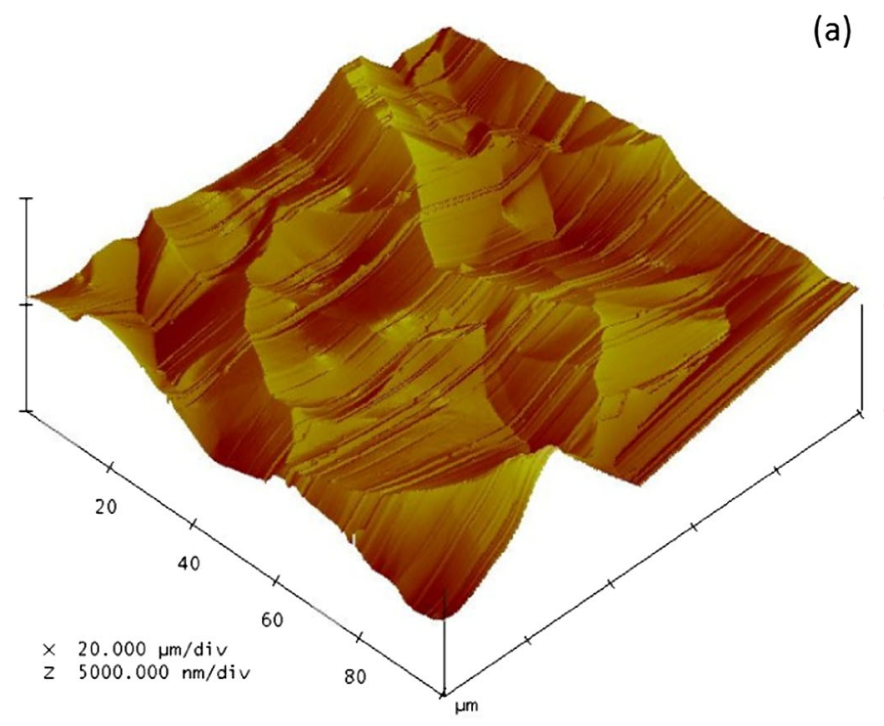

(a)

(b)
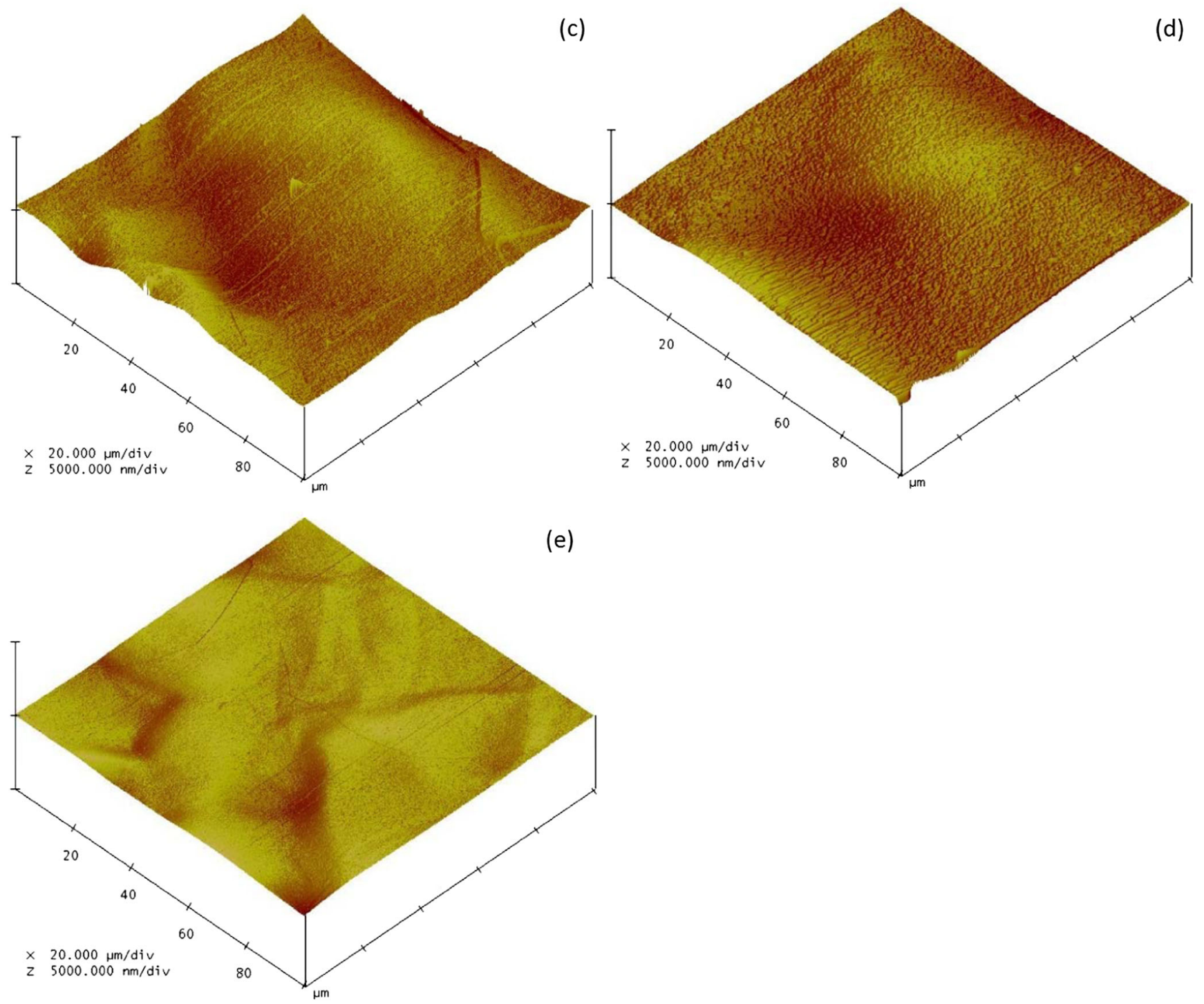

FIG. 10. AFM images from a niobium sample with (a), about $100 \mu \mathrm{m}$ removal by $\mathrm{BCP}$, then incrementally electropolished at $30^{\circ} \mathrm{C}$ to remove (b), $12 \mu \mathrm{m}$, (c) $24 \mu \mathrm{m}$, (d) $36 \mu \mathrm{m}$, or (e) $48 \mu \mathrm{m}$. Horizontal scale is $20 \mu \mathrm{m}$ per division and vertical scale is $5 \mu \mathrm{m}$ per division. 

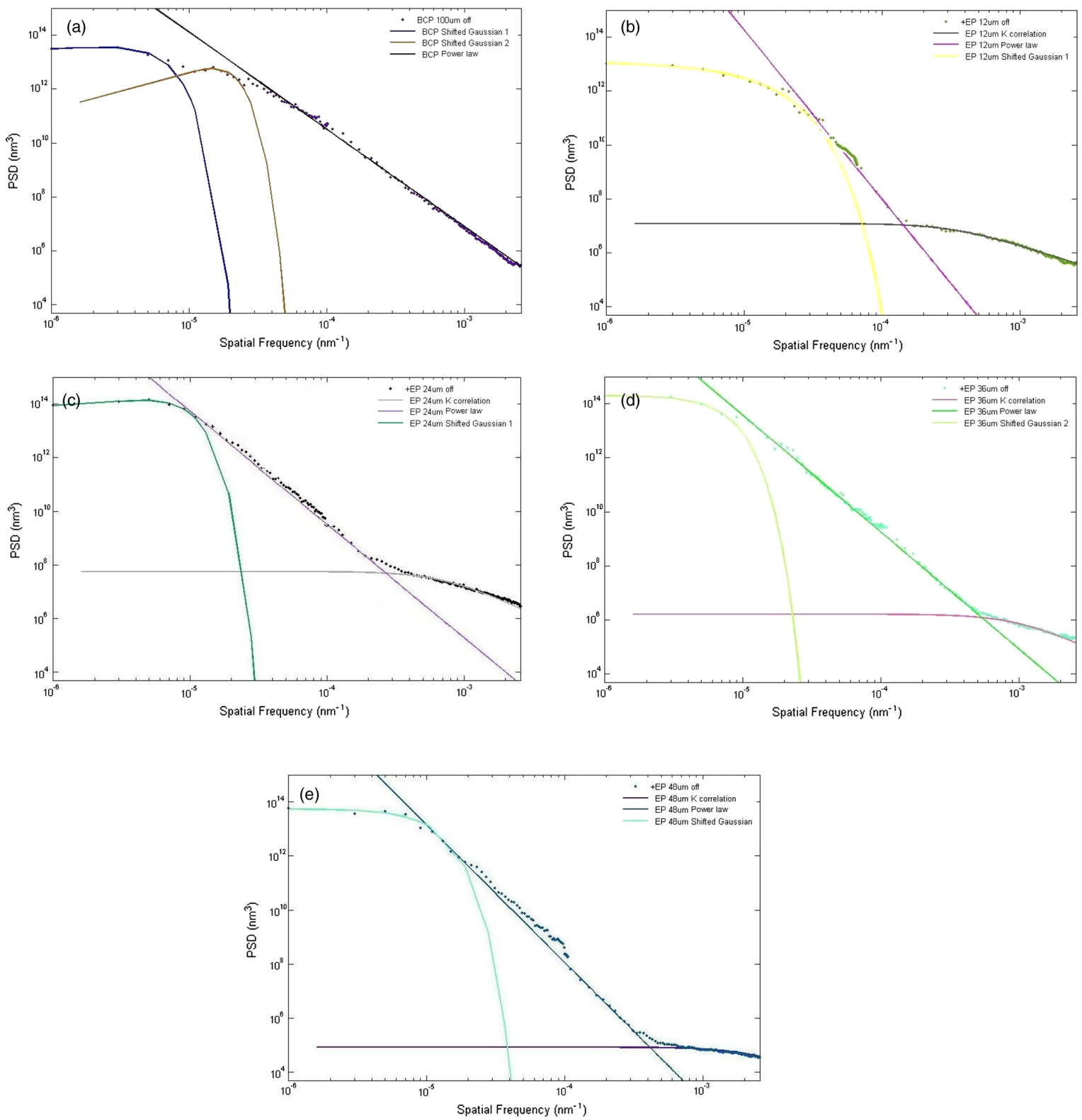

FIG. 11. PSD after different electropolishing durations with initial state of buffered chemical polishing (a) $100 \mu \mathrm{m}$ BCP, (b) $+12 \mu \mathrm{m}$ EP, (c) $+24 \mu \mathrm{m}$ EP, (d) $+36 \mu \mathrm{m}$ EP, and (e) $+48 \mu \mathrm{m}$ EP PSD with regional fitting. These long duration electropolishing treatments are conducted at $30^{\circ} \mathrm{C}$ and AFM scanned with size $100 \mu \mathrm{m} \times 100 \mu \mathrm{m}$.

TABLE IX. Fitting parameter of Samples (unit: nm) for Fig. 11 (Frequency range applicable).

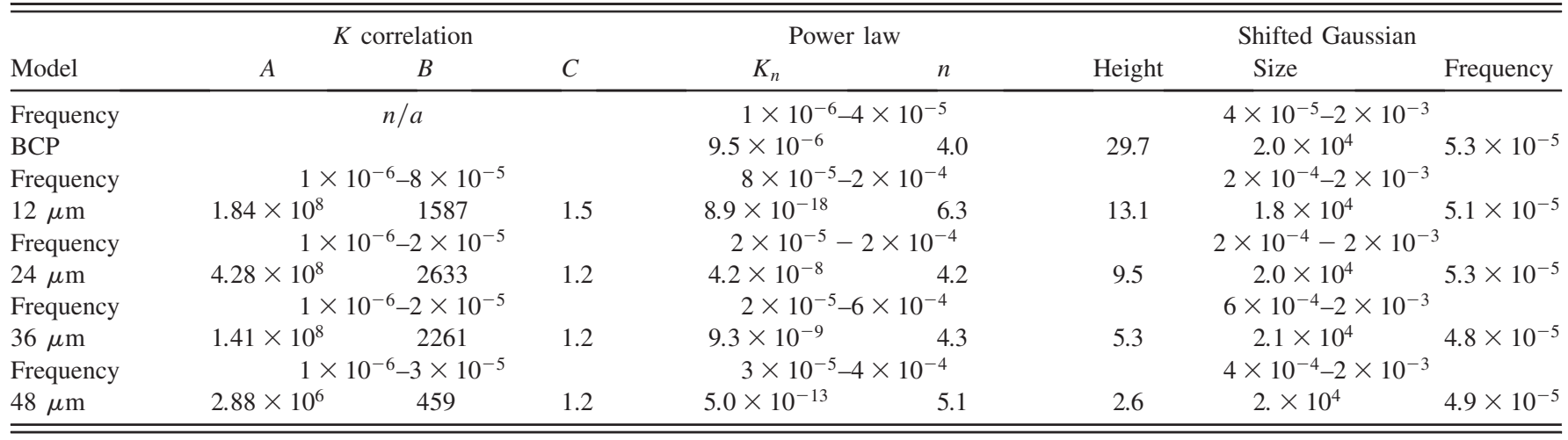




\section{CONCLUSIONS}

Detailed analysis of the topographic power spectral density of processed niobium surfaces sheds additional light on the mechanisms that yield these surfaces and raises further questions, potentially having practical consequence. Significantly more information is needed, but its acquisition by AFM is a truly daunting task. However, we find that polishing duration and temperature can have predictable effects on the evolution of power law features and superstructures at different scale regions in PSD spectra. This predictability may aid in the development of a more thoroughly optimized production process for SRF cavities yielding the best possible performance for accelerators.

\section{ACKNOWLEDGMENTS}

This paper was authored by Jefferson Science Associates, LLC under U.S. DOE Contract No. DEAC05-06OR23177. Chen $\mathrm{Xu}$ is grateful for discussions with Dr. Peter Takacs and Mrs. Olga Trofimova.

[1] H. Padamsee, J. Knobloch, and T. Hays, $R F$ Superconductivity for Accelerators (Wiley and Sons, New York, 2008), 2nd ed. [http://www.wiley.com/ WileyCDA/WileyTitle/productCd-3527408428.html].
[2] Hui Tian, Charles E. Reece, Michael J. Kelley, Shancai Wang, Lukasz Plucinski, Kevin E. Smith, and Matthew M. Nowell, Appl. Surf. Sci. 253, 1236 (2006).

[3] D. Landolt, Electrochim. Acta 32, 1 (1987).

[4] Hui Tian and Charles E. Reece, Phys. Rev. ST Accel. Beams 13, 083502 (2010).

[5] Chen Xu, Hui Tian, Charles E. Reece, and Michael J. Kelley, Phys. Rev. ST Accel. Beams 14, 123501 (2011).

[6] A. Burrill, G. K. Davis, F. Marhauser, C.E. Reece, A. V. Reilly, and M. Stirbet, in Proceedings of the International Particle Accelerator Conference, San Sebastian, Spain 2011, mooca01 [http://accelconf.web.cern.ch/AccelConf/ IPAC2011/papers/mooca01.pdf].

[7] Hui Tian, Guilhem Ribeill, Chen $\mathrm{Xu}$, Charles E. Reece, and Michael J. Kelley, Appl. Surf. Sci. 257, 4781 (2011).

[8] American Society of Mechanical Engineers Standard No. B46.1 (2002) [http://www.asme.org/kb/standards].

[9] Josep Ferré-Borrull, Angela Duparré, and Etienne Quesnel, Appl. Opt. 40, 2190 (2001).

[10] M. Senthilkumar, N. K. Sahoo, S. Thakur, and R. B. Tokas, Appl. Surf. Sci. 252, 1608 (2005).

[11] Josep Ferré-Borrull, Angela Duparré, and Etienne Quesnel, Appl. Opt. 40, 2190 (2001).

[12] P. A. Jacquet, Nature (London) 135, 1076 (1935). 